\title{
Investigating the information gaps in refugee integration
}

\author{
Olubukola Oduntan \\ Dept. of Computer and Information Sciences \\ University of Strathclyde \\ 26 Richmond Street, Glasgow G1 1XH \\ olubukola.oduntan@strath.ac.uk
}

\author{
lan Ruthven \\ Dept. of Computer and Information Sciences \\ University of Strathclyde \\ 26 Richmond Street, Glasgow G1 1XH \\ ian.ruthven@strath.ac.uk
}

\begin{abstract}
Refugee integration processes and systems are complex for refugees. They find them difficult to navigate and thus often end up disadvantaged. This paper presents the first set of findings from an ongoing information behaviour research study into refugee integration. The study explores the situational experiences of refugees and asylum seekers engaging with the integration processes and systems through individual semi-structured interviews. Dervin's sense-making methodology was used to elicit the information gaps. The findings reveals refused asylum situation during integration and highlight information needs embedded in processes and systems of refugee integration. The results have implications for reducing the complexity of service provision during refugee integration. In addition, the approach expands previous studies and highlights the depth a situational investigation can bring to information behaviour studies.
\end{abstract}

\section{Keywords}

Human information behaviour, refugee integration, sensemaking, situational information behaviour.

\section{INTRODUCTION}

Refugee integration is a complicated phenomenon that attempts to deal with the sociological and psychological consequences of forced displacement. It deals with the changing relationship between refugees and host societies. However, due to complex integration systems and processes, refugees often end up marginalised. The design and delivery of integration services and systems is therefore pivotal for successful integration of refugees. The aim of this research is to understand the information behaviour of refugees and identify information gaps in situations as they seek integration into the host country. This knowledge can be used to inform and enhance the design and delivery of integration provisions. In this paper, the information gaps surrounding refused asylum situation is discussed.

[This is the space reserved for copyright notices.]

ASIST 2017,. Crystal City, VA | Oct. 27-Nov 1, 2017

[Author Retains Copyright. Insert personal or institutional copyright notice here.]

\section{LITERATURE REVIEW}

Information behaviour focuses on information needs, seeking and use. It concerns the creation of information as well as the processes in service of information transfer to solve problems (Bates, 1999) and design products and services (Borko, 1968). The role of information behaviour studies in any given context is therefore to inform the design of person-centred services and systems through the identified information needs, sources and seeking behaviour. However, it could be particularly daunting with marginalised groups, especially refugees as challenges of access and disparate contextual factors for conception are encountered. This is further complicated by the differing terminologies used for these groups. As a result, the majority of information studies have centred on general migrant information behaviour whilst refugee specific ones are slowly emerging.

The identified information needs of general migrant include: social, cultural knowledge and skill-based knowledge (Fisher, Durrance, \& Hinton, 2004); health insurance, emergency care, vaccinations, dental, preventive care, pregnancy, what to expect from health services, school enrolment, housing and employment (Courtright, 2005). Silvio (2006) identified academic, apprenticeship, health, employment, political and how to deal with discrimination and Shoham \& Strauss (2008) identified housing, schooling, health, driving, banking, legal issues, work and language. Lingel (2011) identified information need around neighborhood, grocery shopping, local routes, libraries and hospitals. These studies also identified a broad range of information sources that included family and friends (Shoham \& Strauss, 2008) and social networks such as ball parks, bike shops, day care centers, church, barber shops, hair salons and garage (Fisher et al., 2004).

However, these information needs are at an individual-level and are set within certain specific confined instances. Individual-level information needs isolate the studied from either others in a process and surrounding contextual factors of situations. For instance, Fisher et al. (2004) studied the use of library programs by the Queens Borough public library and Courtright (2005) studied health information seeking investigation of Latino newcomers to Southern Indiana in the United States. Similarly, Shoham \& Strauss (2008) investigated the information needs of new immigrants' families from North America to Israel and 
Lingel (2011) studied new immigrants at an international center.

The refugee specific studies includes the work of Lloyd, Kennan, Thompson, \& Qayyum (2013) that identified information needs around everyday living and compliance, and Lloyd (2014) that identified health information needs. The information sources identified included trusted mediators, social networks and visual sources. These studies, like the general migrants studies, were individuallevel and set within confined instances: Lloyd (2014) studied African refugees and focused on health while Lloyd et al. (2013) studied newly arrived refugees. In this study, we examine contextual and individual variables including sociological processes in refugee integration for the identification of refugee information needs.

Although information needs, sources and seeking behaviour have indeed been identified, they do not address the processes and procedural dimensions involved. This may be attributed to Wilson (1981) observation of "a failure to identify with the situations within which information needs investigations are carried out". It is advocated that a holistic approach to migrant information studies be adopted, encompassing closer examination of theories and principles of social inclusion and social capital in addition to information behaviour (Caidi, Allard, \& Quirke, 2010).

Information behaviour studies being person-centred need not only identify individual-level information needs. The scope of identified information needs can be broadened. A situational approach to information behaviour during refugee integration can provide fuller perspectives to help understand the relationships between contextual factors and human information behaviour in situations which can be used in the actual design of services and provision. This is because information needs identified from situations put any potential person in context.

\section{CONCEPTUAL BASIS}

Those who are forced displaced i.e. refugees and asylum seekers are a challenging population to study. Their integration discussion cuts across social, political, economic, structural, socio-cultural and institutional dimensions. In this study, facts, theories and practices of refugee integration were synthesised with theories of information behaviour (Oduntan, 2017). The key topics surrounding refugee integration and information behaviour are discussed in this section. It covers integration, refugee integration systems and the concept of a situational information behaviour in refugee integration.

\section{Integration}

The humanitarian crisis in the world has continued to escalate. Presently, the UNHCR records over 65 million forcibly displaced persons in the world and refugee integration is now of global concern. However, the concept of integration is "individualised, contested and contextual" (Robinson, 1998). It varies by country depending on the interests, value and perspective of the people concerned, and changes over time (Castles, Korac, Vasta, \& Vertovec, 2002). It involves many actors, agencies, logics and rationalities, disparate range of state policies, laws, local initiatives and societal dispositions and the interplay of these agendas (Sigona, 2005).

Integration is surrounded by discussions of whose integration is to be examined as 'migrants' is a broad term consisting of many categories. The Council of Europe argued that integration deals with the changing relationship between migrants in general and host societies (Council of Europe, 1997) but the Economic Council on Exiles and Refugees (ECRE) argued that refugees have additional and distinctive needs than other types of migrants thus the integration emphasis is on refugees (ECRE, 2002).

There is a consensus that integration is not straightforward: it is a process of change that is dynamic, two-way, long term and multidimensional (ECRE, 2002). There are processes and systems in host countries to facilitate integration, but, ultimately these are unfamiliar processes, systems and cultures for the migrant especially the refugees who may not have planned their migration, suffer considerable loss, trauma and dislocation amongst others (Korac, 2003). This situation could be made worse by their experiences of navigating the processes and systems for integration in the new country.

\section{Refugee Integration Systems}

Globally 'refuging' is a right guided according to the UN 1951 Refugee Convention which describes a refugee as someone who "owing to a well-founded fear of being persecuted for reasons of race, religion, nationality, membership of a particular social group or political opinion, is outside the country of his nationality and is unable or owing to such fear, is unwilling to avail himself of the protection of that country". Host countries appropriate the convention as applicable in individual integration systems which are evaluated.

For instance, in the United Kingdom, refugee integration is defined as "the process that takes place when refugees are empowered to achieve their full potentials as members of British society, to contribute to the community, access public services and to become fully able to exercise the rights and responsibilities that they share with other residents in the UK" (Home Office, 2004). Integration is evaluated with an Indicator of Integration framework that includes employment, housing, education and health.

The UN convention is operated in an asylum system in which refugees arrive under different elements. The systems incorporate varied levels of access to provisions including support, benefits, work entitlements and rights to remain. Thus refugee integration starts on arrival in the host country through the transition process.

There are primarily two categories of persons navigating the integration system. Firstly, there is the asylum seeker: a 
person who arrived into the country on their own. They have applied for protection and are awaiting decision. The asylum seeker have minimum access to provisions until granted refugee status. Secondly there is the refugee: this is a person accepted either after an asylum application in the host country or by selection from refugee camps or their home country. Such persons have maximum access to provisions and support. However, irrespective of the level of access to provisions, they face the same processes and systems which are unfamiliar and new to them (Da Lomba, 2010).

Refuge seekers are expected to successfully achieve integration over time with the provided processes and systems. However, integration literatures have described the navigation of these processes and systems by the refugees as cumbersome which has devastating consequences on emotional health and other aspects of personal integration. (Favell, 2001); (Heckmann et al., 2001); (Sigona, 2005); (Zetter, Griffiths, \& Sigona, 2005).

The UNHCR reports that over $80 \%$ of refugees live below the poverty line in host countries (UNHCR, 2016). This might be related to the cumbersome processes that results in insurmountable difficult situations and the stalling of their integration journey. Thus, in the identification of information needs, there is a need to put into perspective the cumbersome processes and difficult situations during integration. This information behaviour study is approached from a situational angle. A situational perspective enables a focus on the situations in the sociological processes to elicit the information gaps-in-situations.

\section{Situational Information Behaviour}

The idea of situations in information behaviour is founded on context. This approach can be traced to Dervin (1976, 1983) that proposed complex communication based approach for the contextual study of information needs, seeking and use. This notion of context is also supported by Wilson (1981) that stated the context of any information needs may be the person themselves, or the role demands of the person's work or life, or the environments including political, economic, technological amongst others within which that life or work takes place.

The power of context for information behaviour studies have been expounded through the literatures including Belkin (1980), Kuhlthau (1993) and Wilson (1997), to name a few. Context is also the feature of the progress and numerous developments achieved in the field. For instance Savolainen's Everyday Life Information Seeking (Savolainen, 1995), Sonnenwald's Information Horizon (Sonnenwald, 1999) and Fisher's Information Grounds (Pettigrew, 1999). Contexts are multi-dimensional and can be described by a variety of attributes and one of the many attributes of context is situation (Brenda Dervin, 2003). Sonnenwald (1999) expanded on situation expressing that situations may be characterised by actions or behaviours that occur over time and are connected by participants, further, that there may be a variety of situations and a flow of situations arises within any context. Cool (2001) summed situation as a focus of analysis in its own right as it has the potential for bringing together both individual cognitive-level and social-level analyses of human information behaviour. Situations are therefore subcontextual circumstances where information gaps may be identified following from the above.

\section{Context $\rightarrow$ Situations $\rightarrow$ Information Needs}

Information needs, sources and seeking behaviour are always a by-product of any information studies as has been shown. However, focusing on the power of the situations in a context will specifically target fundamental information needs in and from situations that provides a fuller capacity for inclusion into the design of services and not only in the isolation of provision of services. This promotes further the importance of person-centred investigations and eliminates the limitation of individual-level needs. A situational information behaviour investigation is thus most appropriate in the refugee integration context. This will avoid Wilson (1981) observation of "failure to identify with the situations within which information needs arises" and heed Caidi (2010) advice of "a holistic approach to immigrant's information studies" highlighted earlier.

\section{Information behaviour and refugee integration}

Refugee integration is evidently a complicated social process that takes place over time. Information behaviour follows the red thread of information in the social lives of people (Bates, 1999). Refugees find themselves in numerous situations where perhaps a flow of situations arises. In information behaviour, situations are the dynamic environments in which interpretive processes unfolds (Cool, 2001). The situations in refugee integration are a focus for information behaviour study because of the complexities they are characterised by. A couple of inherent complexities are briefly highlighted as a complete discussion of the complexities of refugee integration is not possible.

Firstly, the key word in the UN convention is "persecution" but it has no single definition. Persecutions can be for various reasons as defined by the host country and the scope of persecutions for each host country keeps expanding and evolving with time. Secondly, there are numerous routes of arrival into the host country integration systems. This is alongside the earlier highlighted categories of persons in the integration system. Refugee integration is indeed a complicated phenomenon, a situational information behaviour approach is the only chance that all the variables in the complexity will be factored into the understanding. 


\section{RESEARCH DESIGN}

The study adopts an idiographic socio-cognitive approach (Bates, 2005) informed by Dervin sense-making methodology. Sense-making uses a situation-gap-outcome metaphor to investigate human experiences (Dervin, 2003). The focus is on where one is coming from, what one is struggling with and where one is going. Refugees navigating the processes and systems in an unfamiliar country are in a move across time-space, they are on an integration journey and the evidence of this journey is their story (Oduntan, 2016). Information behaviour in refugee integration can therefore be accounted using the sensemaking metaphor on refugee experiences. The situationgap-outcome metaphor was used in the design of semistructured interviews taking a cue from the sense-making methodology micro-moment timeline interview (Dervin, 2003). As such, participants recounted their experiences situationally and the information gaps in the situations elicited. The research received ethical approval from the University of Strathclyde ethical board.

The study population was 20 participants: 11 female participants and 9 male participants. Their age ranged between 15 and 50.2 of the participants were minors (accompanied by parents) and 5 were part of families with young children. 2 participants arrived as minors but at the time of interviews were adults. 10 participants had elementary education and 10 graduate level. Participants had lived between 1 month and 15 years in the host society at the time of data collection between July and December 2016.

The population consisted of 12 asylum seekers and 8 refugees. Participants were recruited through diversity sampling rather than snowballing, as the latter might have resulted in access to only a specific group either by age or geography. The population geography spans 14 countries including the top countries in the United Kingdom Home Office list of nationalities applying for asylum - Iran, Iraq, Pakistan, Eritrea, Afghanistan and Syria (Home Office, 2016). This wide breadth in countries enables a multidimensional exploration of the integration processes and systems experiences since integration is meant for all irrespective of origin.

\begin{tabular}{|l|l|}
\hline Persecution & Number of participant \\
\hline Business persecution & 3 \\
\hline Political persecution & 2 \\
\hline Safety & 3 \\
\hline Religious persecution & 3 \\
\hline Sexual persecution & 1 \\
\hline War & 8 \\
\hline
\end{tabular}

Table 1. Persecution Reasons
Table 1 shows the broad range of reasons for persecution in the study population. The reasons include business, political, safety, religious, sexual and war. This highlights the many definition that can be attributed to the persecution in the UN convention. Likewise, there is no one way of arrival into the system. Table 2 shows the routes of arrival identified in this study population. The routes are road

\begin{tabular}{|l|l|}
\hline Route & Number of participants \\
\hline Road travel & 7 \\
\hline Port of entry & 4 \\
\hline In-country & 6 \\
\hline Humanitarian/Reunion & 3 \\
\hline
\end{tabular}

Table 2. Arrival Routes

travel, port of entry, in-country and humanitarian/family reunion. The road travel route includes those that traveled by road through countries including those that journeyed through the Mediterranean Sea. The port of entry route includes those that travelled by air into the host country and applied for asylum at the airport. The in-country route are those that have been in the country for other reasons and now cannot go back to their home countries for fear of persecution.

The humanitarian/family reunion route includes those that have been given protection status or visa from their home countries. There are two sides to this, either humanitarian as a result of government going to recruit refugees in refugee camps amongst other places, or family reunion taken by a refugee already in the host country inviting their family to join them. These arrival routes in relation to the earlier highlighted categories of persons in the integration systems implies the first 3 arrival routes in Table 2 start the integration journey as asylum seekers while those from the humanitarian/family reunion route starts as refugees.

20 narrative semi-structured interviews were completed. All interviews were audio recorded and transcribed by the first author. The average interview lasted $1 \mathrm{hr} 5$ minutes. Only two of the participants required an interpreter whilst a few others who did not require an interpreter took time in articulating responses to questions. Data was thematically analysed and coded in an iterative process based on the commonalities and diversities in experiences. This allowed a connection to be made between the individual and contextual factors which enabled the circling out of information gaps in the experiences as they navigated the processes and systems. The emergent themes and patterns from the different experiences were sorted and labelled. Quotes as spoken directly by participants are highlighted in the findings and discussion section to support the themes. Participants requested anonymity, as a result quotes are not identified. 


\section{FINDINGS AND DISCUSSION}

The benefit of a situational approach became immediately apparent as the contextual variables of refugee integration and their effect on information behaviour soon emerged. Asylum applications can be refused before being granted refugee status, and there are sociological provisions for it thus it is a part of the integration process. The first set of information gaps that emerged were around the refused asylum situation. In this section, the information needs and the information sources in asylum refusal situation are discussed. This first set of findings part answers one of the research questions in the ongoing study: "What are the information gaps during refugee integration"?

\section{Asylum refusal}

Asylum refusal is when an asylum application has received negative decision. There are sociological provisions associated with this decision however it is surrounded by restrictions and limitation. The asylum process starts with an asylum application submitted to the Home Office - the UK immigration authority. On submission of the application, the asylum seeker is provided with financial support and accommodation through service providers while waiting for decision. This is called the waiting period (in this population sample the waiting period was between 1-6 months).

The positives of the waiting period is stability for asylum applicants while waiting for the asylum decision. This matched participants' anticipation of a "safe haven"

"When I got to this country, I was like the happiest man in the world, I was so glad. I planned for what I had to do; everything I had to do for my life like how I could go to the university, get married, get a house, have a beautiful life like everyone"

However, upon receiving a refusal, the data suggests the abruptness with which the new found stability comes to end is like a sudden crush on utopia. Participants all said they felt lost. They did not understand why they were not granted asylum after the journey that was made, and they did not know what to do.

"I am still confused now about everything; I am confused about what I have to do next"

This is because as soon as a negative asylum decision is made, the financial support might stop:

"The money stop, I am stressed, what will I eat?"

They might be sent out of their accommodation:

"The letter came that I should leave the house, I wondered where I will go, where I will sleep? Again another headache problem"

If not immediately deported after this decision, the refused asylum seeker might be required to fulfil certain conditions such as signing regularly at the Home Office.
"Even when I was in pain that I could not walk, they forced me to come and sign or else they will stop the money"

All refused asylum seekers associated this time with uncertainty, confusion, depression, ill health amongst others. This included the in-country applicants who may be thought of as having the advantage of being in the country already but they also do not understand the process.

Some participants expressed frustration at the reasons for their refusal. They felt like it was like the end of the world especially the newly arrived asylum seekers.

"After the interview one month later they refused, they say I am lying I am not from Eritrea. When they refused, they say I am not a Christian when I am even a singer in church, I got confused. I ask myself all the time who am I? So I have a court appointment, I took all my photo etc. Then the court said I am a Christian but not Eritrean. I am confused more"

It is a time of helplessness: some refused asylum seekers while attending the immigration authority office to sign documents are removed to a detention center such as Dungavel - a detention center in Glasgow. They are either sent back into society or deported after 1 or 2 months. 3 of the asylum seekers in this study population have been detained at Dungavel and 2 have been in and out of detention a number of times.

"I went to the Home Office to report as usual then they ask me to meet the manager in the office, then I went there and they bring me to Dungavel"

Participants that had been to Dungavel had difficulties settling back into society after detention.

"When I was released from Dungavel, actually I slept on the street that night. That state was painful, cold and hungry. I went to charities they said no, I went to police station, they said no you can't sleep here. I was trying to get somewhere to sleep and go back to Edinburgh with zero money"

Asylum refusal is an extreme situation during integration. It is a time of erratic uncertainty. The daily financial support may stop and suddenly start again. Some participants don't know what happens next after the refusal, even though they are often given appeal options, unfortunately most do not understand it. It is a period of numerous events for which the asylum seekers are not prepared, as they have no information on how to deal with it. The information gapsin-situations were circled out from the experiences as it arose during their journey. The identified information gaps in refused asylum situation are detailed below.

\section{Legal}

Although refuge seeking is humanitarian, there are legal implications in the host countries. Asylum refusal is in 
particular a legal issue because refused asylum seekers are allowed to appeal the asylum decision until a time when the appeal is exhausted. The legal information gaps centred on:

\section{Solicitor}

The data showed participants were unclear about solicitor roles and reputation despite how crucial they were to the process. This was irrespective of the level of education. A graduate level participant said:

\section{"They gave me a paper to call the lawyer but they did not tell me what to call the lawyer for"}

There is no dignity in the selection of solicitors as there is no way offered to select solicitors such as by reputation.

"They gave us a list of contacts for immigration lawyers I ask them which one is a good solicitor and they say they are all $O K$ and can pick whichever one you like"

For most, it is an interpreter who takes them to a legal firm. Solicitors send staff as representatives to promote their services - an employee that speaks the language of the asylum seekers.

"When we are coming new, one boy works with a lawyer as an interpreter and any new person to red road, he comes and takes them to the lawyer, so he took me to the lawyer"

For some such as in detention centers, contact with solicitors are through a drop-in while for others they are given a contact list by the official service providers only.

"The solicitor do not help you get out, they only say when you get out call me"

There were issues of complacency, poor treatment and discrimination. All participants said the solicitors treated their cases poorly but they continued working with the solicitor for fear of the consequences. All participants who were refused asylum on their first application attributed this to the solicitor while those successful on first application said a solicitor was not needed until asylum was refused. Either way, this can be associated to the lack of information on the roles of the solicitor and selection criteria.

"It took him 2 months to finish my assessment just to translate and write everything which is too long"

Some did not know lawyers were free. In an exceptional case one in-country participant struggled with payments to a lawyer until informed of Legal Aid - the government financial support for the costs of legal advice.

\section{Appeals and Court}

The data showed dealing with appeals and the different courts processes was an area of difficulty. A few refused participants did not understand what the process entailed and the implications:
"Now, I like Glasgow people. But the system do not do me good. I am not killing anyone or fighting and they tell me to go to court"

The reasons for this can be multidimensional, though might be related to their level of education but it could also be a cultural issue. There is a need for appeals and courts practices to be clear. Some did not know how to deal with the appeals. Some do not know what it is called:

"When they refused I got confused, so I have another court appointment, I took all my photo etc."

The other "court appointment" is an appeal, where more evidence is required to defend the refusal. Others did not know what to do when they felt discriminated against. An in-country applicant said:

"I was called a liar, a criminal, my kids were told to go back to where their color origin from, when they are 18 they should come back"

It is evident that dealing with legal processes is complicated for the refused asylum seeker and the arrival route appeared to have an impact on the experiences.

\section{Housing}

The experiences showed asylum housing is surrounded by numerous issues. The UK Home Office provides accommodation through a service provider - all participants complained of the attitudes, lack of respect, approaches and poor treatment by the accommodation provider and they had no information on how to deal with it.

"The service providers don't treat us like humans, they treat us treat us like $s^{* *}$ "'

\section{Content}

There were breach of privacy experiences. Half the study population were not provided information on what was allowed in the allocated flats. Participants said the service providers visited the provided accommodation in the absence of occupants to check the contents of the house especially electronic appliances. The outcome of those visits are often traumatic: it may include the Home Office suddenly stopping support for asylum seekers possessing electronics such as television or tablets in the accommodation. For example, an asylum seeker in Glasgow was asked to go to London:

"Now the Home Office stop the money because I have a television and ask me to appeal it at the first hearing tribunal in London"

\section{Eviction}

There is no eviction procedure. 8 of the asylum seekers had experienced an attempt by the service provider to lock them out of the accommodation in their absence. Participants indicated not being given any notification to prepare them for the event and being unaware of how to deal with the situation. 
"I put my key it did not go in, I was worried what do I do, then I call my solicitor then solicitor said he will contact the service provider to find what happened. The owner turned up and was introduced and he said I'm not supposed to be there that I should go to friends, I told him I had no friend, I have nowhere to go. So he knocks on the door and a man with a box of tools comes out embarrassed and I went in quick because I know once I went inside there is no way, they'll move me, they said I have 24 hours to move out and leave. Once they left you start thinking, it's so painful, so stressful don't know how to put it"

The data suggested eviction resulted in homelessness. The refused asylum participants had no information on where to get help or how to deal with homelessness.

"I got a letter from the Home Office that my asylum is refused. They take the flat keys from me, I was homeless for 1 month. They did not tell me anything, nothing”

Homelessness and destitution often end up being a recurring event for the refused asylum seeker as refused asylum decision are appealed repeatedly until they are eventually granted status.

\section{Allocation}

There were issues around accommodation sharing that revolved around tolerance. It is not clear how flats are shared but appeared to be between people of different nationalities and languages. Participants were not provided information on the rules of co-habitation. Quite a number of participant had difficulties agreeing with flatmates on issues of cleanliness, visitors, late nights etc.

"My flatmate said he is not able to clean the bathroom because he does not speak English and I said to him you do not need to speak English to clean yourself"

This may appear domestic and not require the involvement of authorities, however the existence of co-habitation rules will not only drastically reduce disputes but most importantly will prolong the life of the asylum accommodation, as quite a number of these homes end up being demolished.

\section{Education}

Participants had no information on what education is accessible. This particularly concerned the minors in the population. A young participant said

\footnotetext{
"I never knew I go to school, I stayed at home for 7 months until a day my mum took me to a meeting with the council that was when we were told I go to school"
}

Although, adult refused asylum seekers are not entitled to formal education, minors are entitled to formal education until the end of high school.

The minor participants had no information on how to fulfil the education curriculum requirements. For instance the education curriculum requires work experience as part of high school however immigration laws prevents the asylum seeker from any form of employment.

"All my friends are on work experience but I can't because I am asylum seeker so I stay at home"

This was a major dilemma for the young participants and they expressed how much they wanted to fully complete the high school education curriculum.

\section{Language}

English language classes were a major difficulty on arrival, especially for those from countries where English is not their first language. Participants had no information on how to get into language classes. It appeared there were many English language classes available however getting into an English class proved difficult. All participant lamented about how long it took to get into a class. A recently arrived asylum seeker broke down in tears during the interview as she discussed her ordeal with language.

\section{"The most important thing for me is the language, I can't speak any English, I can't do anything without it"}

Participants had no information on the boundaries of the roles of service providers during integration. Half the research population got into language classes by themselves after waiting for the service providers for a period of time.

\section{Social}

Participants had difficulties forming bonds in society, and as a result resorted to staying indoors.

"I stay indoor all day because I am afraid to go out, I only go out when I have appointment with the lawyer or Home Office"

This also included minors that did not know how to tell their schoolmates they were asylum seekers.

\section{Extra-curricular}

The minors that have been refused asylum with their parents had no information on how to attend events and make friends. They did not know how to go on camping trips, beach trips and prom like other kids in school. They had no information on how to access the required attire for special events.

\footnotetext{
"There was this charity shop and I saw this very nice dress, it was $£ 10$ but I cannot afford it and asked them can I borrow it for 1 day and return it and they asked why do you need it and I said for
} 
prom and she said if you can't afford a dress for a party then don't think to go to the party"

The circumstances surrounding asylum refusal are tough and it appeared that the authorities understands the implications of the actions but the goals are unclear.

"I go to the Home Office every Friday to sign and every time the Home Office ask me who help you"

The measures surrounding the provision for refused asylum seekers creates destitution which could be tantamount to desperate situations. This unfortunately forces hooliganism and bears considerable psychological and physical trauma on the individuals. This was understandably evident in the behaviour of some of the participants who involuntarily turned aggressive during interviews

"I feel like I am like in a prison, though I am in safety but in a big prison",

The irony of these actions results when such persons are eventually granted status: it would seem that the society gets a now emotionally unstable person, considering how long refused asylum seekers may live in the country. The period of asylum refusal for this study population was between 11 months and 11 years.

These information needs identified from the refused asylum situation provide a two-way benefit that will mitigate refused asylum circumstances significantly for both asylum seekers and the host society. They will guide the availability of appropriate information to asylum seekers and enable the design of person-centred integration services by the host society, which will alleviate the marginalisation of refugees in the long term.

\section{Information Sources}

Information sources are also outcomes of information behaviour studies. The identified information sources during refused asylum include:

\section{Friends}

Friends were the most popular source of information consistent with previous research (Lingel, 2011), (Silvio, 2006), (Courtright, 2005) (Fisher et al., 2004). A participant said her friend from the English class told her she could go to a computer school. Another participant heard about volunteering from friends. For another it was a friend that told him to go to service providers for transport support to fulfil an identity request by the Home Office.

"We did not know these things existed but when you talk to people we get information about what is for us"

Friends included inmates at the detention center. A participant currently in their $11^{\text {th }}$ year as a refused asylum seeker said:
"All through this times I look for friends to talk to, some who are in the same situation or someone who can speak my language"

Internet

The Internet was a common source of information in this study population.

'I went to the library close to the accommodation and used the computers to get information about schooling'

Only 3 participants did not use the Internet. This is as a result of their inability to speak English.

\section{Interpreters}

Interpreters emerged as a key source of information for the non-native English speakers in the study population.

"I trust to go with him go the lawyer because he can speak my language"

This applied especially for getting a lawyer and local travel.

\section{Caseworkers}

A caseworker is assigned by service providers to facilitate the provision of services to refugees and asylum seekers.

"My caseworker gave me advice, she gave me everything in a paper and showed me everything and where I can go to college"

These sources of information are not completely surprising considering the participant were dealing with asylum refusal. Friends such as people in similar situations will be more comfortable sources of information. As one of them accurately compared

"The condition is really different between asylum seeker and refugee, if you come as a refugee lots of people help you there is benefit and support from service providers but who come as asylum seeker no one help them they start from zero"

Furthermore, the information sources could be implied to emphasize the role of social capital and its types in the integration of refugees explicated in Oduntan (2017). Bonding social capital of close family and friends in this case just friends. Bridging social capital of loose friends and workmates as seen in participants that got information from inmates at the prison. Linking social capital of people out further as in the participants that got information from case workers and interpreters. 


\section{CONCLUSION}

Refugee integration systems are indeed complicated sociological processes that refugees and asylum seekers journey through in numerous dissimilar states. The study findings pinpoints refused asylum as one of the states in refugee integration and highlights the information needs embedded in this situation. The situational information behaviour approach enabled a new kind of generalisable findings that honours diversity and individuality while at the same time addressing the human universals in refugee integration such as legal aspects, education aspects and others. The idea of situational information need extends the outreach of person-centred investigations and eliminates the isolation of individual-level needs.

The research data demonstrated the systems complexity and individual complications in refugee integration processes. Firstly, refugee integration is not straightforward. In addition to the individual factors such as the origin, the level of education, the journey and others, there are numerous reasons for persecution - the key word in the UN 1951 convention statement. Secondly, there are numerous routes of arrival into the system. These characteristics emphasise diversity as a strength for situational information behaviour studies.

The research findings shows that information behaviour can be used to inform and enhance the design of integration services and provisions. The information behaviour in refused asylum situation revealed information needs across legal, accommodation, education and social dimensions. These have implications for the design of person-centred sociological provisions by the host society while providing for availability of information to asylum seekers during refugee integration. In addition, the identified information sources - friends, internet, interpreters and caseworkers, have implications for access to information and service delivery during refugee integration.

The findings also suggests the likely existence of other unexplored situations in refugee integration which can be the subject of further research locally and internationally. Refugee integration is a revolving geopolitical issue that will always be complicated, however the understandings from information behaviour investigations will reveal the emergent information needs at any given point in time strengthening the capacity of integration provisions and services.

\section{ACKNOWLEDGMENTS}

I would like to especially thank my research participants, refugees and asylum seekers, for their openness. I am also grateful for the support of Strathclyde iSchool Research Group.

\section{REFERENCES}

Bates, M. J. (1999). The Invisible Substrate of Information Science. Journal of the American Society for Information Science, 1999, Vol.50(12), p.1043-50, 50(12).
Bates, M. J. (2005). An Introduction to Metatheories, Theories, and Models. Medford, NJ: Information Today, In Fisher, Karen E., Erdelez, Sanda, and McKechnie, Lynne, Eds. Theories of Information Behavior.

Belkin, N. J. (1980). Anomalous states of knowledge as a basis for information retrieval. Canadian Journal of

Information Science, 5, 133-143.

Borko, H. (1968). Information Science: what is it? American Documentation, 19, 3-5.

Caidi, N., Allard, D., \& Quirke, L. (2010). Information practices of immigrants. Annual Review of Information Science and Technology, 2010, Vol.44, pp.493-531, 44.

Castles, S., Korac, M., Vasta, E., \& Vertovec, S. (2002). Integration: Mapping the Field.

Cool, C. (2001). The concept of situation in information science. Annual Review of

Information Science and Technology, 35, 5-42.

Council of Europe. (1997). Measurement and Indicators of Integration.

Courtright, C. (2005). Health information- seeking among Latino newcomers - an exploratory study. Information Research: an international electronic journal, 10(2), 224.

Da Lomba, S. (2010). Legal Status and Refugee Integration: a UK Perspective. Journal of Refugee Studies, 2010, Vol. 23(4), pp.415-436, 23(4).

Dervin, B. (1976). Strategies for dealing with human information needs: Information or communication? Journal of Broadcasting, 1976, Vol.20(3), p.323-333, 20(3).

Dervin, B. (1983). An overview of sense-making research: concepts, methods and results to date. Paper presented at the International Communication Association Annual meeting, Dallas.

Dervin, B. (2003). Given a context by any other name: Methodological tools for taming the unruly beast. In B. Dervin \& L. Foreman-Wernet (Eds.), Sense-Making methodology reader:selected writings of Brenda Dervin. Cresskill, NJ: Hampton Press.

Dervin, B. (2003). A theoretic perspective and research approach for generating research helpful to communication practice. In B. Dervin \& L. ForemanWernet (Eds.), Sense-Making methodology reader:selected writings of Brenda Dervin. Cresskill, NJ: Hampton Press.

ECRE, Economic Council on Refugees and Exile. (2002). Position on the integration of Refugees in Europe.

Favell, A. (2001). Integration policy and integration research in Europe: a review and critique. In T. A. Aleinikoff \& D. B. Klusmeyer (Eds.), Citizenship Today: Global Perspectives and Practices (pp. 349-399). Washington, DC: Brookings Institute/ Carnegie Endowment for International Peace. 
Fisher, K. E., Durrance, J. C., \& Hinton, M. B. (2004). Information grounds and the use of need- based services by immigrants in queens, New York: A context- based, outcome evaluation approach. Journal of the American Society for Information Science and Technology, 55(8), 754-766. doi: 10.1002/asi.20019

Heckmann, F., Lederer, H., Worbs, S., Dominique, S., Krief, P., \& Peignard, E. (2001). Effectiveness of National Integration Strategies Towards Second Generation Migrant Youth in a Comparative European Perspective.

Home Office, UK. (2004). Integration Matters: A National Strategy for Refugee Integration. http://217.35.77.12/archive/England/papers/welfare/pdfs/ COI NATI.pdf: Home Office.

Home Office, UK. (2016). Immigration Statistics, April to June 2016. https://www.gov.uk/government/publications/immigratio n-statistics-april-to-june-2016/asylum\#key-facts

Korac, M. (2003). Integration and how we facilitate it: A comparative study of the settlement experiences of refugees in Italy and the Netherlands. Sociology-The Journal Of The British Sociological Association, 2003 Feb, Vol.37(1), pp.51-68, 37(1).

Kuhlthau, C. (1993). Seeking meaning : a process approach to library and information services. Greenwich CT: Ablex publishing company.

Lingel, J. (2011). Information tactics of immigrants in urban environments. Information Research, December 2011, Vol.16(4), 16(4).

Lloyd, A. (2014). Building Information Resilience: How do Resettling Refugees Connect with Health Information in Regional Landscapes - Implications for Health Literacy. Australian Academic \&amp; Research Libraries, 45(1), 48-66. doi: 10.1080/00048623.2014.884916

Lloyd, A., Kennan, M. A., Thompson, K. M., \& Qayyum, A. (2013). Connecting with new information landscapes: information literacy practices of refugees. Journal of Documentation, 2013, Vol.69(1), p.121-144, 69(1).

Oduntan, O. (Producer). (2016). Doctoral Student Research Video Competition: Information Behaviour of Refugees.

Oduntan, O. (2017). Information Behavior of Refugees: Viewing Refugee Integration Through an Information Science Lens. Bulletin of the Association for Information Science and Technology, 43(3), 63-69. doi: 10.1002/bul2.2017.1720430320
Pettigrew, K. E. (1999). Waiting for chiropody: contextual results from an ethnographic study of the information behaviour among attendees at community clinics. Information Processing and Management, 35(6), 801817. doi: 10.1016/S0306-4573(99)00027-8

Robinson, V. (1998). Defining and measuring successful refugee integration. Proceedings of ECRE International conference on Integration of Refugees in Europe: European Council on Refugees and Exiles.

Savolainen, R. (1995). Everyday life information seeking: Approaching information seeking in the context of " way of life". Library and Information Science Research, 1995, Vol.17(3), pp.259-294, 17(3).

Shoham, S., \& Strauss, S. (2008). Immigrants information needs: their role in the absorption process. Information Research-An International Electronic Journal, 13(4).

Sigona, N. (2005). Refugee Integration( s): Policy and Practice in the European Union. Refugee Survey Quarterly, 2005, Vol.24(4), pp.115-122, 24(4).

Silvio, D. H. (2006). The information needs and information seeking behaviour of immigrant southern Sudanese youth in the city of London, Ontario: an exploratory study. Library Review, 55(4), 259-266. doi: 10.1108/00242530610660807

Sonnenwald, D. H. (1999). Evolving Perspectives of Human Information Behavior: Contexts, Situations, Social Networks and Information Horizons. Paper presented at the Exploring the Contexts of Information Behavior: Proceedings of the Second International Conference in Information needs, seeking and use in different contexts, Sheffield England.

UNHCR, United Nations High Commissioner for Refugees. (2016). UNHCR Global Trends Report - 2015 in review. UNHCR Global Trends Report - 2016 June, p1-67.

Wilson, T. D. (1981). On user studies and information needs. Journal of Documentation, 1981, Vol.37(1), pp.3$15,37(1)$.

Wilson, T. D. (1997). Information behaviour: An interdisciplinary perspective. Information Processing and Management, 1997, Vol.33(4), pp.551-572, 33(4).

Zetter, R., Griffiths, D., \& Sigona, N. (2005). Social capital or social exclusion? The impact of asylum-seeker dispersal on UK refugee community organizations. Community Development Journal, 2005, Vol.40(2), pp.169-181, 40(2). 